International

Medical Society

http://imedicalsociety.org

\title{
Evaluating Cost of Materials for Wound Care Provided to Patients at Home
}

\section{Sandra Marina Gonçalves Bezerra1, Aline Costa de Oliveira ${ }^{2}$, Lídya Tolstenko Nogueira ${ }^{3}$, Maria Clara Batista da Rocha Viana ${ }^{4}$, Juliana Lima Nascimento ${ }^{5}$, Maria do Livramento Fortes Figueiredo ${ }^{6}$}

\section{Abstract}

Purpose: to evaluate the dressing material costs provided to patients under home care for the public service of Brazilian health relate with the socio-demographic profile, the type of wound, and associated comorbidities.

Design: Documentary, cross-sectional study with a quantitative approach.

Subjects and setting: The sample consisted of 334 medical records filed by the public health service that provided materials and covers to patients with wounds registered in primary care in the city of Teresina, state of Piauí, Brazil, to perform dressing in domicile.

Methods: Utilization of a semi-structured instrument for collecting data, containing information about the sociodemographic profile, comorbidities, number of wounds and cost of materials dispensed. In the inferential analysis, we used the Kruskal-Wallis test and the MannWhitney test to compare the total costs of treatment.

Results: There was a predominance of men (65.5\%), elderly (49.1\%), with a prevalence of pressure ulcers $(44.6 \%)$, in which the main cover was the collagenase (53.9\%) followed by essential fatty acids (41.1\%). The maximum cost of treatment was US\$ 5,883.05 with a dispensing time of up to five years. There was a significant association between the sociodemographic and clinical characteristics, the kind of wound and treatment time related to the cost.
1 Nurse, Assistant Professor I of the State University of Piauí, Stomatherapist nurse. PhD Nurse in PPGEnf-UFPI.

2 Nurse, Master degree student in PostGraduation Program of the Federal University of Piauí, PPGEnf-UFPI.

3 Nurse, Associated Professor of PPGEnfUFPI.

4 Graduated nurse at State University of Piauí.

5 Pharmacist and manager of the Pharmaceutical Assistance of Municipal Health Foundation of Teresina.

6 Nurse, Associated Professor of PPGEnfUFPI.

\section{Contact information:}

\section{Sandra Marina Gonçalves Bezerra}

Address: State University of Piauí. Nursing coordination. Medical Sciences College, FACIME. Rua Olavo Bilac, 2335, Centro Zip Code: 64001-280, Teresina, Piauí, Brazil.

\section{戸 sandramarina20@hotmail.com}


Conclusion: The cost of materials for dressing in public service is high with inadequate cover and prolonged treatment time, and the pressure ulcer the most expensive.

\section{Keywords}

Health Evaluation; Cost and Cost Analysis; Primary Health Care; Wound Healing; Bandages.

\section{Introduction}

The treatment of wounds is a public health problem, in which the skin lesions that do not heal in a period less than three months are considered chronic and are part of a quiet epidemic affecting the world's population and it is threatening the health economy. It is estimated that in the United States the wounds affect 6.5 million patients, at a cost of US\$ 25 billion annually, which may be related to an aging population and rising rates of obesity and diabetes [1].

Countries of universal public systems have been concerned with effective measures to fund the treatment. In a study conducted in the United Kingdom showed that one of the measures for cost reduction is the use of prophylactic coverage that assists in the prevention and reduction of pressure ulcers (PU) in hospitals. The annual cost for treating PU varied according to the depth of the lesion between 1,000 (superficial) to 17,000 (deep) pounds per year, confirming the importance of preventive measures. The majority predisposition for PU was observed in patients under intensive care, long-term care, or during lengthy procedures performed in the surgical center; and sacral regions, calcaneus, and other bone extremities were at greater risk [2].

Economic evaluation in health and the rational use of medical and hospital supplies are extremely important in the management of public health institutions' resources in Brazil, considering that ex- penditure in this area are increasing while available resources do not increase at the same rate [3].

Another important factor is the thorough observation of changes in cutaneous mucosa integrity and cellular abnormalities, which can inhibit healing to occur to them. A concept used is the Wound Bed Preparation (WBP), which conducts to a systematic approach to skin care and the benefits, which is the increase of healing rate and consequent reduction in the cost of treatment, promoted by advanced therapies [4].

For nurses, it is important to develop protocols in the care of patients with wound at home in order to support the planning of nursing care and perform guidance to family members and caregivers in order to reduce direct and indirect costs, and improve quality the patient's life [5].

The objective of the study was to evaluate the dressing material costs provided by the public health service to patients under home care, in relation to socio-demographic profile, the kind of wound and associated comorbidities.

\section{Methods}

It is a cross-sectional study based on document analysis, with a quantitative approach, developed at the Municipal Health Foundation, public service department of the city of Teresina, situated in the state of Piauí, Brazil, responsible for the archiving 
records and providing of materials and cover for patients, with wounds, registered in Primary Care for performing dressing at home. The population of the study consisted of 780 medical records, and of these total, 366 were excluded for not meeting the inclusion criteria, resulting in a sample of 334 medical records of patients attended at home for wounds treatment. The inclusion criteria were individuals from both gender, of all ages, in the treatment of wounds of various etiologies, who received material for taking care of dressing at home. The study excluded incomplete medical records and with a supply of materials and medicines for other purposes such as medicines for oral use, material for intermittent and indwelling urinary catheterization.

\section{Methods}

The instrument used in this research was divided into four parts: Socio-demographic data (age and sex of the patient); clinical data (comorbidities, etiology of the wounds, treatment time and mobility); the provided materials (the type of dressing materials, the cost of materials); and monthly total expense per patient. Comorbidities were categorized according to the International Classification of Diseases (ICD 10): endocrine diseases, circulatory diseases, and injuries from external causes.

\section{Study procedures}

The research was conducted in the city of Teresina, state of Piauí, in the period from January to March of 2015. The instrument was filled out by researchers, according to the information provided in the records, which were filed in folders identified in alphabetical order, with records from patient's data regarding the sociodemographic and clinical profile, motive of the request, description of requested materials and the cost of monthly layoff separated by unit value of each item and the total price. The authorization of the provided material for home use was made by solicitation of the monthly ordered, requested by the doctor or nurse of the primary health care, according to the material and cover established by public service.

\section{Data Analysis}

The data were analyzed using the Statistical Package for the Social Sciences ${ }^{\circledR}$, version 18.0, generating descriptive statistics such as mean, median, standard deviation, interquartile range, minimum and maximum for quantitative variables. For variables with a level of quality measurement, frequencies were calculated. In the inferential analysis, we used the Kruskal-Wallis one-way analysis of variance, in which the significant points have been checked by means of Tukey's Honestly Significant Difference (HSD) test, and the Mann-Whitney U test to compare the total costs of the treatments, with verification of data normality by the Kolmogorov-Smirnov test, with a confidence interval of $95 \%$ and significance of $5 \%$. The research has met national and international standards of scientific research involving human subjects.

\section{Results}

All the 334 patients treated at home for treatment of wounds were characterized in terms of sociodemographic and clinical aspects. They are presented also its relations with the total costs of supplied materials. Table 1 describes the sociodemographic and clinical profile of study participants.

The analyzed sample found a prevalence of male patients 219 (65.6\%), elderly 165 (49.4\%), in which the average age was $61.00( \pm 28.0)$ years. As for comorbidities stands out the injuries from external causes (28.4\%) as spinal cord injury, cranioencephalic trauma, fractures, amputation, in most due to automobile accidents, followed by accidents with fire gun, leading many patients to a permanent situation of bedridden. Other clinical factors involved were burns, complications of internal orthopedic prosthetic devices and surgical complications. 
Table 1. Sociodemographic and clinical characteristics of patients receiving dressing materials at home and relations with the total costs of the materials supplied. Teresina, PI, Brazil, 2016.

\begin{tabular}{|c|c|c|c|c|c|}
\hline \multirow{2}{*}{ Variables } & \multirow{2}{*}{$\begin{array}{c}n \\
(\%)\end{array}$} & \multicolumn{3}{|c|}{ Total Cost (US\$)* } & \multirow{2}{*}{$\begin{array}{c}p \\
\text { value }\end{array}$} \\
\hline & & $\operatorname{Me}( \pm I R)$ & Min & Max & \\
\hline \multicolumn{6}{|l|}{ Age } \\
\hline Up to 20 years & $\begin{array}{c}17 \\
(5.1)\end{array}$ & $\begin{array}{c}41.7 \\
(89.9)\end{array}$ & 28.6 & 3780.3 & $<0.001^{a}$ \\
\hline 21 to 59 years & $\begin{array}{c}139 \\
(41.6)\end{array}$ & $\begin{array}{c}165.3 \\
(357.1)\end{array}$ & 8.5 & 3312.9 & $0.270^{c}$ \\
\hline $\begin{array}{l}60 \text { years or } \\
\text { more }\end{array}$ & $\begin{array}{c}165 \\
(49.4)\end{array}$ & $\begin{array}{c}166.7 \\
(527.7)\end{array}$ & 7.3 & 5883.1 & \\
\hline Not Informed & $\begin{array}{c}13 \\
(3.9)\end{array}$ & $\begin{array}{c}41.7 \\
(89.9)\end{array}$ & 14.0 & 293.6 & \\
\hline $\mathrm{Me}( \pm \mid \mathrm{R})$ & \multicolumn{5}{|c|}{$61.0(28.0)$} \\
\hline \multicolumn{6}{|l|}{ Gender } \\
\hline Male & $\begin{array}{c}219 \\
(65.6)\end{array}$ & $\begin{array}{c}103.2 \\
(327.2)\end{array}$ & 8.4 & 5883.1 & \multirow{2}{*}{$0.195^{b}$} \\
\hline Female & $\begin{array}{c}115 \\
(34.4)\end{array}$ & $\begin{array}{c}82.1 \\
(227.2)\end{array}$ & 7.3 & 2683.8 & \\
\hline \multicolumn{6}{|l|}{ Comorbidities } \\
\hline $\begin{array}{l}\text { Endocrine } \\
\text { Disorders }\end{array}$ & $\begin{array}{c}57 \\
(17.1)\end{array}$ & $\begin{array}{c}55.2 \\
(90.5)\end{array}$ & 11.7 & 279.8 & \multirow{6}{*}{$0.001^{a}$} \\
\hline $\begin{array}{l}\text { Circulatory } \\
\text { diseases }\end{array}$ & $\begin{array}{c}50 \\
(14.9)\end{array}$ & $\begin{array}{c}132.0 \\
(403.5)\end{array}$ & 7.3 & 5883.0 & \\
\hline $\begin{array}{l}\text { Nervous system } \\
\text { disease }\end{array}$ & $\begin{array}{c}33 \\
(10.0)\end{array}$ & $\begin{array}{c}149.2 \\
(436.2)\end{array}$ & 26.9 & 780.3 & \\
\hline $\begin{array}{l}\text { Injuries from } \\
\text { external causes }\end{array}$ & $\begin{array}{c}95 \\
(28.4)\end{array}$ & $\begin{array}{c}149.1 \\
(483.8)\end{array}$ & 8.8 & 975.0 & \\
\hline Others & $\begin{array}{c}37 \\
(11.1)\end{array}$ & $\begin{array}{c}107.2 \\
(351.3)\end{array}$ & 8.4 & 1200.5 & \\
\hline Not informed & $\begin{array}{c}62 \\
(18.5)\end{array}$ & $\begin{array}{c}64.4 \\
(151.4)\end{array}$ & 38.1 & 2574.4 & \\
\hline \multicolumn{6}{|l|}{ Mobility } \\
\hline Ambulate & $\begin{array}{c}20 \\
(6.0)\end{array}$ & $\begin{array}{c}66.4 \\
(255.0)\end{array}$ & 7.3 & 1482.1 & \multirow{4}{*}{$0.001 a$} \\
\hline $\begin{array}{l}\text { Ambulate with } \\
\text { support }\end{array}$ & $\begin{array}{c}61 \\
(18.3)\end{array}$ & $\begin{array}{c}64.8 \\
(190.3)\end{array}$ & 14.2 & 1279.8 & \\
\hline $\begin{array}{l}\text { Do not } \\
\text { Ambulate }\end{array}$ & $\begin{array}{c}191 \\
(57.1)\end{array}$ & $\begin{array}{c}135.1 \\
(421.4)\end{array}$ & 11.3 & 5883.0 & \\
\hline Not informed & $\begin{array}{c}62 \\
(18.6)\end{array}$ & $\begin{array}{c}62.4 \\
(131.9)\end{array}$ & 8.6 & 2574.4 & \\
\hline Total & $\begin{array}{c}334 \\
(100)\end{array}$ & $\begin{array}{c}100.6 \\
(281.8)\end{array}$ & 7.3 & 5883.0 & \\
\hline
\end{tabular}

Endocrine disorders 57 (17.1\%) were substantially comprised of diabetic patients, and in the group of cardiovascular diseases 50 (14.9\%) there were patients with hypertension, myocardial infarction, stroke (ischemic or hemorrhagic), vascular disease, aneurysms, among others. The main diseases of the nervous system 33 (10.0\%) were Alzheimer's disease, Parkson disease, multiple sclerosis and neuropathy. The other category 37 (11.1\%) includes diseases such as neoplasms, leprosy after effects, erysipelas, epidermolysis bullosa, myelomeningocele. In 62 (18.5\%) of the medical records, there was no record of the disease.

About the mobility of patients, the majority 191 (57.1\%) did not ambulate, having as the main cause the after effects from stroke, cerebral palsy and spinal cord injury. The most common reasons for patients who ambulate with assistance 61 (18.3\%) were the result of traumatic injuries and ulcers of the lower limbs. In some medical records, there was no information 62 (18.6\%) and the mobility of the patient had been included in the unknown category. The results obtained to compare the cost, according to the profile of patients, including age, sex, comorbidities and mobility, were statistically treated as non-parametric data.

Table 1 shows a comparison of the total value and groups of variables, where some have indicated significant statistical differences $(p<0.05)$. Regarding variable age, there was a statistically significant difference between costs $(p<0.001)$, and the post hoc of Tukey revealed it among patients 21 to 59 years and those with 60 years or more. Thus, elderly patients who developed wounds required a treatment of major financial value, with a maximum cost of US\$5883.00.

Regarding gender, male patients were those with the highest cost of materials for dressings, with the median value US\$103.2, and a maximum of US\$ 5883.0 As for comorbidities, multiple comparison test was applied, in which was observed a significant difference between some groups, that 
despite having different comorbidities quantitative, presents a similar cost average, such as endocrine disorders and diseases of the circulatory system $(p=0.047)$; endocrine disorders and diseases of the nervous system $(p=0.001)$; endocrine diseases and injuries from external causes $(p=0.009)$; nervous system disorders and uninformed $(p=0.006)$; Injuries from external causes and not informed $(p=0.040)$.

Comparing mobility, it was observed that the category that do not ambulate had a significant quantitative when compared to the group who ambulate with assistance $(p=0.006)$ and not informed $(p=0.005)$.

Table 2 describes the kinds of supplies for cleaning and cover that were requested by the patients. Among the cleaning supplies are: compresses (95.8\%), saline solution (90.1\%) and gloves (85.6\%); among cover materials, collagenase (26.3\%) and Essential Fatty Acids (EFA) were the most requested, but for most patients (50.9\%) there was no disposed material for cover.

Regarding the types of wounds in Table 3 stood out the pressure ulcers (PU) 149 (44.6\%), followed by lower limb ulcers 60 (18.0\%) of various etiologies such as vascular, arterial and diabetic ulcers. Among the traumatic wounds 57 (17.1\%) the main causes were automobile accidents, and surgical incision dehiscence. In the other category 20 (6.0\%) were burns, oncologic wound and Fournier syndrome. In some medical records 48 (14.4\%), was not informed the etiology of the wound.

The analysis found a statistically significant difference between pressure ulcers and ulcer of the lower limbs groups $(p=0.012)$, traumatic wounds $(p=0.001)$, other $(p=0.025)$ and not informed $(p=0.044)$. The PU's had higher average compared to other etiologies of wounds with a value of US\$ 168.64 .

Most of the medical records of the patients, 255 (76.3\%), had a time for provided material for ban-

Table 2. Description of cleaning supplies and provided cover for dressing in patients under home care. Teresina, PI, 2015.

\begin{tabular}{l|c|c|}
\multicolumn{1}{|c|}{ Domains/Facets } & Average & Median \\
\hline Variables & N & $\%$ \\
\hline Compresses & 320 & 95.8 \\
\hline Gloves & 286 & 85.6 \\
\hline Saline solution 0.9\% & 301 & 90.1 \\
\hline Court plaster & 275 & 81.4 \\
\hline Roll bandage & 147 & 44.0 \\
\hline Essential Fatty Acids & 67 & 20.1 \\
\hline Collagenase & 88 & 26.3 \\
\hline Sulfadiazine & 3 & 0.9 \\
\hline Vaseline & 5 & 1.5 \\
\hline Not used & 170 & 50.9 \\
\hline Total & 334 & $-*$ \\
\hline \multicolumn{1}{|c|}{ Source: Medical records filed at the Pharmaceutical } \\
* Tanagement. Teresina, 2015.
\end{tabular}

Table 3. Descriptive statistics of the total value and time of treatment related to the etiology of wounds of patients receiving curative material at home. Teresina 2015.

\begin{tabular}{|c|c|c|c|c|c|c|c|c|c|}
\hline \multirow{2}{*}{ Etiology } & \multirow{2}{*}{$N(\%)$} & \multicolumn{3}{|c|}{ Cost of treatment (U\$\$) } & \multirow{2}{*}{$p$ value } & \multicolumn{3}{|c|}{ Treatment Time (years) } & \multirow{2}{*}{$p$ value } \\
\hline & & $\mathrm{Me}( \pm \mathrm{IR})$ & Min & Max & & $\mathrm{Me}( \pm \mathrm{IR})$ & Min & Max & \\
\hline Lower limb ulcers & $60(18.0)$ & 7.3(212.9) & 7.3 & 1482.1 & \multirow{5}{*}{$<0.001^{a}$} & $1.2(0.3)$ & 1.0 & 4.0 & \multirow{5}{*}{$0.026^{a}$} \\
\hline Pressure Ulcers & $149(44.0)$ & $13.3(496.2)$ & 13.3 & 5883.1 & & $1.0(1.1)$ & 1.0 & 5.0 & \\
\hline Traumatic wounds & $57(17.1)$ & $8.80(128.7)$ & 8.8 & 2371.3 & & $1.0(0.7)$ & 1.0 & 5.0 & \\
\hline Others & 20(6.0) & $8.4(113.2)$ & 8.4 & 853.1 & & $1.0(0.4)$ & 1.0 & 2.0 & \\
\hline Not informed & $48(14.4)$ & $14.0(160.1)$ & 14.0 & 3780.3 & & $1.0(0.7)$ & 1.0 & 5.0 & \\
\hline
\end{tabular}

Source: Medical records filed at the Pharmaceutical Management. Teresina, 2015. Me( \pm IR): Median ( \pm interquartile range); 
dage of up to one year, 38 (11.4\%) in two years, 24 $(7.2 \%)$ in three years, and the more extended periods as four years and five years showed 8 (2.4\%) and $9(2.7 \%)$, respectively. Only the pressure ulcer presented a significance in the difference with lower limb ulcers $(p=0.011)$, traumatic wounds $(p=0.012)$, other $(p=0.043)$ and the not informed variable $(p=0.022)$ in which, despite of a quantitative of cases superior to the others, it has an average cost of approximately 1 and a half.

\section{Discussion}

The data showed that there was a majority of male, elderly above 60 years with impaired physical mobility, considering that, in the group studied, less than $6 \%$ ambulated. This study corroborates with the research done in home assistance that found similar data [6]. Considering the results and the prospect of increased longevity, related to improved access to health care, it becomes necessary a planning of actions for the prevention of injuries in the elderly.

It can also stand out the high percentage of adults between 21 and 59 years old with injuries resulting from traffic accidents and violent situation. Time series study in Brazil found a $800 \%$ increase in mortality from traffic accidents between the years 1996 and 2009 which showed growth of 0.5 to 4.5/100,000 inhabitants, the highest growth rates were observed in the states of North, Northeast and Midwest [7]. These data indicate that patients with productive age end up off from work, which may interfere with the economic situation of these and their dependents, resulting in early retirement, change in quality of life and increased costs for the state.

Endocrine disorders such as diabetes stood out in patients and may even be the cause of the emergence of wounds such as diabetic foot or the cause of delayed wound healing, and therefore requiring nursing care that considers the clinical aspects of the patient, the signs and symptoms of associated disorders and aspects of the wound. Studies on the relationship between comorbidities, wounds and clinical reasoning are necessary for the team in decision-making for an approach to the patient with wounds, being an interdisciplinary challenge that transcends the treatment of injury [8]. In a randomized study in patients with diabetic foot after surgical debridement it was found that the diabetic foot treatment using the negative-pressure wound therapy (NPWT) compared to conventional therapy is cheaper because it reduces the number of exchanges and the success rate was $90 \%$, while the traditional dressing success rate was $76.6 \%$ [9].

The high rate of patients with injuries from external causes, unable to ambulate such as wheelchair users and bedridden, whether because of spinal cord injury, trauma or stroke after effects may increase complication rates and the consequent increase in costs along with critically ill patients, in favors of appearance of multiple injuries as the PUs. In a study conducted in Nigeria, the numbers of PUs in male patients, victims of spinal cord injured by trauma (falls from their own height) are high and the use of water mattresses has reduced the incidence of PU, emphasizing the importance of preventive measures [10].

In this study, the PU was most frequent injury among those who do not ambulate, confirming the importance of prevention in patients with limited physical conditions such as bedridden and wheelchair users due to increased susceptibility to the development of lesions by pressure in areas of bony prominence. The PU has always been a problem for health services, especially for nursing and multidisciplinary teams, because the incidence, prevalence and treatment characteristics such as infections, the need for surgery intervention for cleaning, hospitalization and consequences in higher costs $[6,7]$.

Patients with extremes of age are the most vulnerable to developing PU, however young patients, victims of traffic accidents and violence which re- 
quire wheelchairs for locomotion develop deep and severe ulcers, especially in the ischial region. The data reflect that pressure ulcers are chronic wounds which tend to develop in a population of patients debilitated and can be a major source of infection and lead to complications such as septicemia, osteomyelitis and even death [1]. The pelvic osteomyelitis is a serious complication of PU and the diagnosis depends on multiple surgical bone biopsies with microbiological and histological analyzes. The most common pathogens were S. aureus (77.1\%) Peptostreptococcus (48.6\%) and Bacteroides (40\%) (40\%) [11].

The lower limb ulcers show a relevant quantity in which the differential diagnosis of lower limb ulcers involves a range of conditions and if there is no treatment of the underlying cause it will not have wound healing; therefore, the correct diagnosis is crucial. Most of these ulcers have a vascular origin, including venous ulcers and arterial ulcers. Neuropathic ulcers occur, especially in diabetic patients and others are mainly dermatologic, where the origin is caused by a variety of conditions such as vasculitis, tumor infections and pyoderma gangrenosum or necrobiosis lipoidica [8].

The time off for dressing and covers materials had a variance of 1-5 years, confirming the prevalence of chronic slow wound healing. When relating the extended time of treatment with the etiology of wounds, considering that the materials are provided to perform a home care by caregivers and family, hangs the question of the frequency of the evaluation of wounds by the doctor and nurse of the primary care health, the reason why the complex wound care task by lay people performing dressing of the wounds at the domicile can result in a chronic and prolonged treatment time.

Among the cleaning supplies, compresses and saline solution were the most requested. This fact is justified because the gauze, in the most of the lesions, is necessary for both cleaning, absorption, and for using as a primary and secondary dressing.
The physiological solution of sodium chloride at $0.9 \%$ acts to clean the wound with salt solutions prior to applying the cover [12]. The fixation materials all stood by the amount of orders, and adhesive dressing and bandage. Regarding the frequency of chronic ulcers in this study, the lesions characteristically open lesions that often require patching, enhance the importance of these items for the dressing. The choice of products to be used in the treatment of wounds must take into account the phase of the healing process, the depth, the type of exudate, and the presence of infection [13].

The covering materials had collagenase and EFA as the most requested covers. Collagenase acts dissolving the collagen holding avascular tissue to the underlying tissue in the wound bed. This product is not active in dry necrosis (eschar) and the additional use of other topical products, such as iodophors and silver, can reduce their therapeutic efficacy [14]. The essential fatty acid may be indicated for the treatment of open wounds, which promote chemotaxis and angiogenesis, and maintain the humidity, accelerating tissue granulation process [15].

In relation to the cost related to the etiology of the wounds, it was found that the besides PU prevail in patients, showed a higher expense compared with other etiologies of wounds. High values for treatment of PU were also found in a survey conducted in the UK, where the value of a PU ranges from 1,214 pounds (category 1) to 14,108 pounds (category IV). Allowing us to conclude that the costs increase with the severity of the PU, because in more severe cases the time to heal extends the incidence of complications [16].

\section{Limitations}

Throughout the research, we found incomplete records, which required the creation of a variable in some categories named as not informed, in order to not losing relevant data for the research. 


\section{Conclusion}

The cost of dressing materials for the long term is high; also, the same wound was treated for one to five years with the same materials, without routine evaluation of an adequacy of treatment based on scientific evidence.

The main wound in primary care is the pressure ulcers in elderly patients, diabetics and bedridden, followed by injured by trauma due to traffic accidents, located in the region of the lower limbs.

The implementation of this protocol is based on scientific evidence for assessing and assisting patients with wounds, in order to provide preventive measures, and the use of appropriate coverings, according to the characteristics of the wound, which can reduce the costs and treatment time, improve self-esteem and quality of life of patients with wounds under homecare.

\section{Conflict of interest}

The authors declare no conflict of interest.

\section{References}

1. Sen CK, Gordillo GM, Roy S, Kirsner R, Lambert L, Hunt TK, et al. Human skin wounds: a major and snowballing threat to public health and the economy. Wound Repair Regen. 2009; 17(6):763-71.

2. Moore Z, Thorpe E. Dressings for pressure ulcer prevention Made Easy. London: Wounds UK. 2015; 11(2):1-4.

3. Lima ACB, Guerra DM. Evaluation of the cost of treating pressure ulcers in hospitalized patients using industrialized dressings. Ciência \& Saúde Coletiva. 2011 16(1):267-277.

4. Halim AS, Khoo T L, Mat Saad A Z. Wound bed preparation from a clinical perspective. Indian J Plast Surg [serial online] 2012 [cited 2015 Dec 9]; 45:193-202. Available from: http://www.ijps. org/text.asp?2012/45/2/193/101277.

5. Rogenski NMB, Kurcgant P. The incidence of pressure ulcers after the implementation of a prevention protocol. Rev. LatinoAm. Enfermagem. 2012 Mar - Abr; 20(2):[07 telas].

6. Bezerra SMG, Luz MHBA, Andrade EMLR, Araújo TME, Teles JBM, Caliri MHL. Prevalence, Associated Factors, and Classification of Pressure Ulcers in Patients With Prolonged Immobilization Enrolled in the Family Health Strategy. Rev. Estima. 2014; 12(3):41-49
7. Martins ET, Boing AF, Peres MA. Motorcycle accident mortality time trends in Brazil, 1996-2009. Rev. Saúde Pública [online]. 2013[cited 2015 Dec 9]; 47(5):931-941.

8. Oliveira BGRB, Castro JBA, Granjeiro JM. Epidemiologic and clinical overview of patients with chronic wounds treated at ambulatory. Rev. enferm. UERJ. 2013 Dec; 21(1): 612-7.

9. Vaidhya N, Panchal A, Anchalia MM. A New Cost-effective Method of NPWT in Diabetic Foot Wound. Indian J Surg. 2015; 77(Suppl 2):525-9.

10. Emejulu JK, Nwadi UV, Obiegbu HO. Does Improvised Waterbed Reduce the Incidence of Pressure Ulcers in Patients with Spinal Injury? Niger J Surg. 2015 Jul-Dec; 21(2):119-23.

11. Brunel AS, Lamy B, Cyteval C, Perrochia H, Téot L, Masson R, et al. Diagnosing Pelvic Osteomyelitis beneath Pressure Ulcers in Spinal Cord Injured patients: a prospective study. Clin Microbiol Infect. 2015 Nov 24. pii: S1198-743X(15)00987-8. doi: 10.1016/j. cmi.2015.11.005. [Epub ahead of print]

12. Velasco M. Diagnostic and Treatment of Leg Ulcers. Actas Dermosifiliogr; 2011 Dec 102(10): 780-90.

13. Costa AMS Matozinhos ACS, Trigueiro PS, Cunha RCG, Moreira LR. Costs of treatment pressure ulcers in long-term care unitit an institution of Minas Gerais. Rev. Enfermagem Revista. 2015 Jan/Abr; 18(1):58-74.

14. Lawall H. Treatment of chronic wounds. Vasa. 2012; 41(6): 396409.

15. Ferreira AM, Souza BMV, Rigotti MA, Loureiro MRD. The use of fatty acids in wound care: an integrative review of the Brazilian literature. Rev Esc Enferm USP. 2012; 46(3):752-60.

16. Dealey C, Posnett J, Walker A. The cost of pressure ulcers in the United Kingdom. University Hospital Birmingham NHS Foundation Trust, Queen Elizabeth Medical Centre, Birmingham, UK 2 Heron evidence Development Itd, UK. 2012; 21(6) 261.

Publish in International Archives of Medicine

International Archives of Medicine is an open access journal publishing articles encompassing all aspects of medical science and clinical practice. IAM is considered a megajournal with independent sections on all areas of medicine. IAM is a really international journal with authors and board members from all around the world. The journal is widely indexed and classified Q2 in category Medicine. 